\title{
Prevalence and predictors of urinary tract infections among children with cerebral palsy in Makurdi, Nigeria*
}

\author{
Emmanuel Adémólá Anígilájéił", Terkaa Terrumun Bitto ${ }^{2}$ \\ ${ }^{1}$ Department of Paediatrics, Benue State University, Makurdi, Nigeria \\ ${ }^{2}$ Department of Paediatrics, Federal Medical Centre, Makurdi, Nigeria \\ Email: "1arademola@yahoo.com
}

Received 4 September 2013; revised 2 October 2013; accepted 10 October 2013

Copyright (C) 2013 Emmanuel Adémólá Anígilájé, Terkaa Terrumun Bitto. This is an open access article distributed under the Creative Commons Attribution License, which permits unrestricted use, distribution, and reproduction in any medium, provided the original work is properly cited.

\section{ABSTRACT}

Background: Children with cerebral palsy (CP) are prone to urinary tract infection (UTI), a common cause of childhood morbidity and mortality. However, there has been no report regarding the prevalence of UTI among this group of children in Nigeria. Objectives: The study aims at determining the prevalence and the possible predictors of UTI in children with CP compared to age and sex matched children without CP. Methods: A prospective cross-sectional study was carried out among consecutive children with $C P$ at the Neurologic Clinic in the Paediatric Department of the Federal Medical Centre, Makurdi, Nigeria, from December 2011 to May 2013. Results: The age range of the studied population was between 2 and 15 years with a mean age of $8.63 \pm 3.83$ years including 30 males and 22 females. UTI was confirmed in 20 (38.5\%) children with cerebral palsy compared to 2 children (3.8\%) without $C P$ ( $p$ value 0.000 ). Among children with CP, Escherichia coli was the commonest organism isolated in $9(9 / 20,45.0 \%)$, Streptococcus faecalis in $4(20.0 \%)$, Staphylococcus aureus in 3 (15\%), while both Proteus spp., and Klebsiella spp., were isolated in 2 children (10.0\%) each. Escherichia coli was also found in the 2 children without CP. All the organisms were resistant to co-trimoxazole, nalidixic acid, nitrofuratoin and amoxiclav, while they were $100 \%$ sensitive to ceftriazone and the quinolones. In a univariate regression, analysis only moderate to severe gross motor dysfunction predicted the risk of UTI (OR = 54.81, 95\%CI, 2.27 - 1324.00, p value 0.014). Conclusion: Efforts should be put in place to aid mobility among children with $\mathrm{CP}$ in or-

*Conflict of interest: none declared.

"Corresponding author. der to reduce risk of UT.

Keywords: Urinary Tract Infection; Cerebral Palsy Children; Prevalence; Predictors

\section{INTRODUCTION}

A child with cerebral palsy has a difficulty in neuromotor control, a non-progressive brain lesion and an injury to the brain that occurred before it was fully matured [1]. Cerebral palsy is a common cause of childhood morbidity [1]. This morbidity comprised of seizure disorders, mental retardation, abnormalities of vision, problems with respiratory muscle and lower urinary tract dysfunctions [1]. The lower urinary tract dysfunctions manifest symptomatically as urinary incontinence, urgency, frequency, hesitancy and urinary tract infection [2]. Possible reasons for the propensity to urinary tract infections include vesicoureteral reflux and incomplete bladder emptying resulting from detrusor hyperreflexia and detrusor sphincter dysynergia [2-5]. In addition, the impaired cognition and the inability to communicate bladder fullness and the need to void, together with an impaired mobility may also explain the tendency to urinary retention and the attendant risk of urinary tract infections $[2,6]$. A prevalence of $2.2 \%-32.5 \%$ of urinary tract infections among cerebral palsy patients has been reported by authors from developed countries $[2,7,8]$. Unfortunately, there has been no report of UTI among patients with cerebral palsy in Nigeria. This study therefore aims at determining the prevalence and predictors of UTI among cerebral palsy patients attending the Paediatric Outpatient Department of a tertiary health facility in Makurdi, Northern Nigeria. This study becomes important because of the potential complications that can result from missed and untreated urinary tract infections in children. 


\section{MATERIALS AND METHODS}

Ethical approval for the study was obtained from the Hospital Research and Ethics Committee. Children were recruited into the study if the parents or caregivers had given their consent. Subjects were consecutive patients with cerebral palsy attending the Neurologic Clinic of the Paediatrics Outpatient Department (POD) of the Federal Medical Centre, Makurdi. Controls were age (to the nearest birthday) and sex matched consecutive children, who were also attending follow-up appointments at the POD having been previously admitted, treated and had recovered from ailments such as severe malaria, lower respiratory tract infections and diarrheal disease. Subjects and controls that had taken antibiotics in the preceding two weeks, those with on-going menses or one who is having vaginal/penile discharge were excluded from the study. Recruitment into the study spanned between December 2011 and May 2013. The clinical, topographical, gross motor dysfunctions and Intelligent Quotients characterizations of the subjects were done by the principal author. The Gross Motor Function Classification System (GMFCS) as previously described was employed to classify the severity of functional impairment in children with cerebral palsy [9]. GMFCS is a 5-level system defined by separating 4 age groups. It emphasizes sitting and walking functions of children, focusing on self-initiation of the action. Patients with GMFCS level $1-2$ were classified as mild, those with level 3 were classified as moderate, and those with level 4 - 5 were classified as severe CP. The intellectual state of the subjects with cerebral palsy could only be tested using the Man-Drawing Quotient by Ziler that has been previously validated by Ebigbo and Izuora among Nigerian children aged 6 to 11 years [10]. Children with Intelligent Quotient $\leq 75 \%$ were considered to be intellectually disabled. A well structured pre-tested questionnaire was employed to obtain information from the parents or the caregivers of the subjects and the controlsregarding other demographic data, history suggestive of urinary tract infection, enuresis, and constipation. Symptoms of urinary tract infections captured include; fever, painful urination (dysuria; either verbally communicated to the mother of the child or mother noticed persistent crying on micturition), frequent micturition (frequency of urination of more than 7 times a day), gross haematuria, cloudy or smelly urine and flank/back pain. Constipation was as defined by The Paris Consensus on Childhood Constipation Terminology (PACCT) [11] "a period of 8 weeks with at least 2 of the following symptoms: defecation frequency less than 3 times per week, fecal incontinence frequency greater than once per week, passage of large stools that clog the toilet, palpable abdominal or rectal fecal mass, stool withholding behavior, or painful defecation". Enuresis was defined according to the fourth edition of the Diagnostic and Statistical Manual of Mental Disorders [12] (DSM-IV) which defines enuresis as involuntary or unintentional repeated voiding of urine, into bed or clothes, which occurs twice a week for at least 3 consecutive months, in a child that is at least 4 years old. Parents or caregivers of subjects and the control were provided with a properly labeled uncontaminated universal bottle for the collection of midstream early morning urine to be brought back when coming for their next clinic visit. The parents or the caregiver was also instructed on how to collect the mid stream urine. Routine personal hygiene is all that was required. When test cannot be done within the first hour of urine collection, urine was stored in the refrigerator (at $4^{\circ} \mathrm{C}$ ) and tested within 4 hours of storage in the refrigerator. Incubation of the urine was carried out on sheep blood agar, McConkey or CLED (cysteine lactose electrolyte deficient) agar using the quantitative loop method. The plates were examined at between $18-24$ hours. A yield of multiple organisms was considered as a contaminant. Sensitivity of organisms was done using the isosensitive tested agar plate and incubated at $37^{\circ} \mathrm{C}$ for 18 - 24 hours. The zones of inhibition greater than 15 $\mathrm{mm}$ were regarded as sensitive. A urine culture was repeated if there was a contaminant yield. Urinalysis was done using Multistix 10SG by BAYER DIAGNOSTIC and urine sediment microscopy in the standard method [13]. Urinalyses were analysed for significant proteinuria, significant haematuria, the presence of nitrite, significant pyuria and significant microscopic pyuria. Radiological investigations including abdominal ultrasound scan (USS) and micturating cystourethrogram (MCUG) were carried out among subjects and control with confirmed UTI.

\section{For the Purpose of This Study, the Following Definitions Were Applied}

Symptomatic bacteriuria (ASB) or asymptomatic urinary tract infection (AUTI) is defined as the quantitative growth of bacteria, greater than or equal to $10^{5}$ colony forming units per millilitre urine of the same organism, on collected midstream urine specimens, in the absence of symptoms of urinary tract infection.

Symptomatic bacteriuria (SB) or symptomatic urinary tract infection (SUTI) is defined as the quantitative growth of bacteria, greater than or equal to $10^{5}$ colony forming units per millilitre urine of the same organism, on collected midstream urine specimens, in the presence of one or more than one of these signs and or symptoms of urinary tract infection including fever, dysuria, gross haematuria, cloudy or smelly urine, frequency of urination and flank/back pain.

Significant proteinuria is a presence of $2+$ or more protein in the urine.

Significant haematuria is a presence of $2+$ or more 
blood in the urine.

Significant pyuria is a presence of $2+$ or more leucocyte in the urine.

Significant microscopic pyuria is white blood cell (WBC) count of 10 and above per high power field (HPF).

\section{DATA ANALYSIS}

The Statistical analysis was done using SPSS version 16. Test between dependent and independent variables was carried out using the Chi-squared test $\left(\chi^{2}\right)$. The logistic regression model was used to determine independent predictors (demographic, signs and symptoms) of urinary tract infection. Only independent variables with $p$ value of $<0.1$ at the bivariate analysis were considered for logistic regression. Odd ratios with $95 \%$ Confidence Intervals were used to measure the strength of the association at the statistical significance level of $\mathrm{p}<0.05$.

\section{RESULTS}

A total of 93 children with cerebral palsy were seen within the study period but only 52 were included in the study. Twenty children did not meet the inclusion criteria. Fourteen children were lost to follow-up, and they could not return the urine specimens. Mothers were unable to obtain urine specimens in 7 children. The age range was between 2 and 15 years with a mean age of $8.63 \pm 3.83$ years including 30 males and 22 females with a male to female ratio of 1:0.7. With respect to the types of cerebral palsy, 19 (36.5\%) had spastic hemiplegia, 16 (30.8\%) had spastic diplegia, $11(21.2 \%)$ had spastic quadriplegia, $4(7.7 \%)$ had a mixed combination of athetosis with spastic hemiplegia and another $2(3.8 \%)$ children with hydrocephalus had ataxic cerebral palsy. Regarding the degree of gross motor dysfunction, 30 (57.7\%) had mild dysfunction including $11(21.2 \%)$ with grade I and 19 $(36.5 \%)$ with grade II. Moderate to severe motor dysfunction is seen in $22(42.3 \%)$ including eight $(15.4 \%)$ with grade 3 , five $(9.6 \%)$ with grade 4 and nine $(17.3 \%)$ with grade 5. Among the 34 children with $\mathrm{CP}$ whose ages were between $6-11$ years and for which Ziler's Man-Drawing Quotient was determined, 9 had scores $\leq$ $75 \%$ (i.e. Intellectually disabled) and 15 had scores above $75 \%$ (Table 1 ).

\subsection{Urinary Symptoms/Signs, Constipation and Urinalyses Findings among Subjects with Cerebral Palsy and Controls without Cerebral Palsy}

Table 2 shows that the symptoms and signs of UTI, a history of constipation, enuresis, a prior history of UTI, urinalyses findings including significant haematuria,
Table 1. Some demographic characteristics, GMFCS and Intelligent Quotients of subjects with CP.

\begin{tabular}{|c|c|c|}
\hline Characteristics & No & Percentage (\%) \\
\hline \multicolumn{3}{|l|}{ Age } \\
\hline$\leq 5$ Years & 13 & 25.0 \\
\hline$>5$ Years & 39 & 75.0 \\
\hline Total & 52 & 100.0 \\
\hline \multicolumn{3}{|l|}{ Gender } \\
\hline Female & 22 & 42.3 \\
\hline Male & 30 & 57.7 \\
\hline Total & 52 & 100.09 \\
\hline \multicolumn{3}{|l|}{ Types of CP } \\
\hline Spastic hemiplegia & 19 & 36.5 \\
\hline Spastic diplegia & 16 & 30.8 \\
\hline Spastic quadriplegia & 11 & 21.2 \\
\hline Ataxic $\mathrm{CP}$ & 02 & 3.8 \\
\hline Mixed & 04 & 7.7 \\
\hline Total & 52 & 100.09 \\
\hline \multicolumn{3}{|l|}{ Gross motor dysfunction } \\
\hline 1 & 11 & 21.2 \\
\hline 2 & 19 & 36.5 \\
\hline 3 & 08 & 15.4 \\
\hline 4 & 05 & 9.6 \\
\hline 5 & 09 & 17.3 \\
\hline Total & 52 & 100.0 \\
\hline \multicolumn{3}{|l|}{ Intellectual disability } \\
\hline No & 15 & 62.5 \\
\hline Yes & 9 & 37.5 \\
\hline Total & 24 & 100.0 \\
\hline
\end{tabular}

significant proteinuria, nitrite, significant pyuria, significant microscopic pyuria and culture proven UTI were significantly more frequent in subjects with cerebral palsy than their age and sex-matched comparators without cerebral palsy (p value $<0.05$ ).

\subsection{Urinary Culture and Sensitivity Patterns among Subjects with Cerebral Palsy and Controls without Cerebral Palsy}

Table 3 shows that urinary tract infection was confirmed in $20(38.5 \%)$ over-five children with cerebral palsy comprising twelve (23.1\%) males and eight $(15.4 \%)$ fe- 
Table 2. Urinary symptoms, constipation and urinalyses findings among subjects with cerebral palsy and controls without cerebral palsy.

\begin{tabular}{|c|c|c|c|}
\hline Characteristics & Cerebral palsy $(n=52)$ & Children without CP $(n=52)$ & p value \\
\hline \multicolumn{4}{|l|}{ Symptoms } \\
\hline Fever & $17(32.7 \%)$ & $2(3.8 \%)$ & 0.0002 \\
\hline Flank/abdominal-pain & $17(32.7 \%)$ & $-(0 \%)$ & 0.0000 \\
\hline Frequency of urination & $27(51.9 \%)$ & $-(0 \%)$ & 0.0000 \\
\hline Dysuria & $8(15.4 \%)$ & $1(1.9 \%)$ & 0.1600 \\
\hline Constipation & $21(40.4 \%)$ & $7(13.5 \%)$ & 0.0026 \\
\hline \multicolumn{4}{|l|}{ Enuresis } \\
\hline $1^{\circ}$ & $22(42.3 \%)$ & $9(17.3 \%)$ & 0.0063 \\
\hline $2^{\circ}$ & $4(7.7 \%)$ & $-(0 \%)$ & 0.0439 \\
\hline Prior history of UTI & $20(38.5 \%)$ & $7(13.5 \%)$ & 0.0045 \\
\hline \multicolumn{4}{|l|}{ Urinalysis } \\
\hline Significant haematuria & $13(25.0 \%)$ & $4(7.7 \%)$ & 0.0189 \\
\hline Significant proteinuria & $15(28.8 \% 0$ & $6(11.5 \%)$ & 0.0301 \\
\hline Significant pyuria & $13(25.0 \%)$ & $4(7.7 \%)$ & 0.0189 \\
\hline Nitrite & $12(23.1 \%)$ & $1(1.9 \%)$ & 0.0015 \\
\hline \multicolumn{4}{|l|}{ Urine microscopy } \\
\hline Significant microscopic pyuria & $12(23.1 \%)$ & $2(3.8 \%)$ & 0.0048 \\
\hline Urine culture & $20(38.5 \%)$ & $2(3.8 \%)$ & 0.0000 \\
\hline
\end{tabular}

Table 3. Urinary culture and sensitivity patterns among subjects with cerebral palsy and controls without cerebral palsy.

\begin{tabular}{ccccccc}
\hline & CP & & & & NO CP \\
\cline { 2 - 6 } & E. coli & Strept. faecalis & Staph. aureus & Proteus spp. & Klebsiella spp. & E. coli \\
\hline No of significant growth & 9 & 4 & 3 & 2 & 2 & 2 \\
Sensitivity ciprofloxacin & $9(100 \%)$ & $4(100 \%)$ & $3(100 \%)$ & $2(100 \%)$ & $2(100 \%)$ & $2(100 \%)$ \\
Ofloxacin & $9(100 \%)$ & $4(100 \%)$ & $3(100 \%)$ & $2(100 \%)$ & $2(100 \%)$ & $2(100 \%)$ \\
Sparfloxacin & $9(100 \%)$ & $4(100 \%)$ & $3(100 \%)$ & $2(100 \%)$ & $2(100 \%)$ & $2(100 \%)$ \\
Ceftriazone & $9(100 \%)$ & $4(100 \%)$ & $3(100 \%)$ & $2(100 \%)$ & $2(100 \%)$ & $2(100 \%)$ \\
Gentamycin & $6(66.7 \%)$ & $4(75 \%)$ & $1(33.3 \%)$ & $1(50 \%)$ & $1(50 \%)$ & $1(50 \%)$ \\
Nalidixic acid & $0(0 \%)$ & $0(0 \%)$ & $0(0 \%)$ & $0(0 \%)$ & $0(0 \%)$ & $0(0 \%)$ \\
Streptomycin & $5(55.6 \%)$ & $2(50 \%)$ & $1(33.3 \%)$ & $1(50 \%)$ & $1(50 \%)$ & $1(50 \%)$ \\
Amoxiclav & $0(0 \%)$ & $0(0 \%)$ & $0(0 \%)$ & $0(0 \%)$ & $0(0 \%)$ & $0(0 \%)$ \\
Tetracycline & $0(0 \%)$ & $0(0 \%)$ & $0(0 \%)$ & $0(0 \%)$ & $0(0 \%)$ & $0(0 \%)$ \\
Cotrimoxazole & $0(0 \%)$ & $0(0 \%)$ & $0(0 \%)$ & $0(0 \%)$ & $0(0 \%)$ & $0(0 \%)$ \\
Nitrofuratoin & $0(0 \%)$ & $0(0 \%)$ & $0(0 \%)$ & $0(0 \%)$ & $0(0 \%)$ & $0(0 \%)$
\end{tabular}

$\overline{\mathrm{CP}}=$ Subjects with cerebral palsy, NO CP = Controls without cerebral palsy, E. coli = Escherichia coli, Staph. aureus $=$ Staphylococcus aureus, Strept. faecalis = Streptococcus faecalis.

males with a male to female ratio of 1.5:1 (p value 0.790 ). Asymptomatic urinary tract infection (AUTI) was seen in $2(10.0 \%)$ children and symptomatic urinary tract infection (SUTI) in the remaining $18(90.0 \%)$ of cerebral palsy children. SUTI was confirmed in 2 controls children without $\mathrm{CP}$.

Escherichia coli were isolated from majority of subjects, $9(9 / 20,45.0 \%)$, streptococcus faecalis in $4(20.0 \%)$, staphylococcus aureus in $3(15 \%)$, while both Proteus spp., and Klebsiella spp., were isolated in 2 children $(10.0 \%)$ each. All the three children with staphylococcus aureus isolates also presented with fever.

The major isolate, Escherichia coli were $100 \%$ sensitive to ciprofloxacin, ofloxacin, sparfloxacin and ceftriazone but less sensitive to gentamycin $(50 \%-66.7 \%)$ and were resistant to nitrofuratoin $(0 \%)$, tetracycline 
$(0 \%)$, cotrimoxazole $(0 \%)$, amoxiclav $(0 \%)$ and nalidixic acid (0\%). Streptococcus faecalis, Staphylococcus aureus, Proteus spp. and Klebsiella spp. were also 100\% sensitive to the quinolones and ceftriazone and were also resistant to nitrofuratoin, tetracycline, cotrimoxazole, amoxiclav and nalidixic acid but were between 33.3\% - 50\% sensitive to streptomycin and between $33.3 \%-75 \%$ sensitive to gentamycin.

\subsection{Abdominal Ultrasound Finding}

Abdominal ultrasound scan among the $20 \mathrm{CP}$ children with UTI revealed no renal parencyhmal abnormality. In 2 female children there were bladder wall thickness, irregularity of the bladder wall, and residual urine. Vesicoureteric reflux (VUR) was seen in only one of the two female children on micturating cystourethrogram. Radiological findings were normal in the two control children without CP. Urodynamic study was not done and causal relationship between the VUR and bladder dysfunction could not be established.

\subsection{Predictors of Urinary Tract Infections}

In bivariate analysis, older children ( $>5$ years), moderate to severe motor disability, dysuria, constipation, flank/ abdominal pain, significant haematuria, significant pyuria and significant microscopic pyuria were found to be significantly associated with UTI ( $p$ values $<0.05$ ). However, in univariate regression analysis only moderate to severe gross motor dysfunction predict the risk of UTI $(\mathrm{OR}=54.81,95 \% \mathrm{CI}, 2.27-1324.00$, p value 0.014$)$. Multivariate regression analysis could not be done, (Tables 4-6).

\section{DISCUSSION}

To the best of the authors' knowledge this is the first study describing the burden of urinary tract infection among Nigerian children with $\mathrm{CP}$ and the prevalence of $38.5 \%$ found in the present study was higher than those documented among other Nigerian children at risk of UTI including those with sickle cell anaemia $(5.8 \%$ $21.6 \%)$ [14-16], malaria $(6 \%$ - 9\%) [17,18], HIV $(10.3 \%)$ [19] and malnutrition $(11 \%-11.3 \%)$ [20,21].

As may be expected, the frequency of UTI in the children with CP (38.5\%) in our study was higher than their comparators without CP $(3.8 \%)$ and the $1 \%-3 \%$ reported in the general paediatric population [22]. The possible reasons for the higher prevalence of UTI among CP children had been enumerated earlier [2-6].

Furthermore, the frequency of UTI of $38.5 \%$ found in the present study is comparable to the $32.5 \%$ reported by Ozturk et al. in Turkey [8], but is much higher than the respective $7.4 \%$ and $2.2 \%$ reported by Reid and Borzy-
Table 4. Association between some characteristics of subjects with CP and presence of UTI.

\begin{tabular}{|c|c|c|c|c|}
\hline Characteristics & UTI & No UTI & $X^{2}$ & $p$ value \\
\hline \multicolumn{5}{|l|}{ Age group } \\
\hline$\leq 5$ years & 0 & 13 & 10.833 & 0.001 \\
\hline$>5$ years & 20 & 19 & & \\
\hline Total & 20 & 32 & & \\
\hline \multicolumn{5}{|l|}{ Gender } \\
\hline Male & 12 & 18 & 0.710 & 0.790 \\
\hline Female & 8 & 14 & & \\
\hline Total & 20 & 32 & & \\
\hline \multicolumn{5}{|l|}{ GMD } \\
\hline Mild & 02 & 28 & 30.286 & 0.000 \\
\hline Moderate/severe & 18 & 04 & & \\
\hline Total & 20 & 32 & & \\
\hline \multicolumn{5}{|c|}{ Intellectual disability } \\
\hline No & 6 & 7 & 0.906 & 0.341 \\
\hline Yes & 3 & 8 & & \\
\hline Total & 9 & 15 & & \\
\hline \multicolumn{5}{|l|}{ Frequency } \\
\hline No & 09 & 16 & 0.123 & 0.726 \\
\hline Yes & 11 & 16 & & \\
\hline Total & 20 & 32 & & \\
\hline \multicolumn{5}{|l|}{ Dysuria } \\
\hline No & 12 & 32 & 15.127 & 0.000 \\
\hline Yes & 08 & 0 & & \\
\hline Total & 20 & 32 & & \\
\hline \multicolumn{5}{|l|}{ Constipation } \\
\hline No & 07 & 24 & 8.179 & 0.004 \\
\hline Yes & 13 & 08 & & \\
\hline Total & 20 & 32 & & \\
\hline \multicolumn{5}{|l|}{ Enuresis } \\
\hline No & 10 & 16 & $<0.001$ & 1.000 \\
\hline Yes & 10 & 16 & & \\
\hline \multicolumn{5}{|l|}{ Total } \\
\hline \multicolumn{5}{|l|}{ Prior history of UTI } \\
\hline No & 11 & 21 & 0.587 & 0.444 \\
\hline Yes & 09 & 11 & & \\
\hline Total & 20 & 32 & & \\
\hline
\end{tabular}

skowski in London [2] and Hellquist et al. in North Carolina [7]. Unlike the present study, antibiotics had been used prior to presentation of the $\mathrm{CP}$ patients in the latter 
two studies [2,7] and may possibly explain the discrepancies in the frequency of the UTI.

Furthermore, the symptoms and signs of UTI, a history of constipation, enuresis, a prior history of UTI, urinalyses findings and culture proven UTI were significantly more frequent in subjects with cerebral palsy than their age and sex-matched comparators without cerebral palsy. Similar findings have also been reported by Ozturk et al. in Turkey [8].

In Univariate regression analysis, only moderate to severe gross motor dysfunction significantly predict the risk of UTI among our subjects with CP. These are children who often have to be carried from one place to the other by their siblings or their parents because of difficulty in mobility and both manually propelled or electrically powered wheelchairs are often beyond the reach of these families. Often, these children are neglected, stationed supine in one place for a long time, majority developing pressure sores on the occiputs and the buttocks and the poor personal hygiene resulting from prolonged

Table 5. Urinalyses findings among subjects with cerebral palsy and the relationship with UTI.

\begin{tabular}{|c|c|c|c|c|}
\hline Characteristics & UTI & No UTI & $\mathrm{X}^{2}$ & $p$ value \\
\hline \multicolumn{5}{|l|}{ Haematuria } \\
\hline No & 10 & 29 & 10.833 & 0.001 \\
\hline Yes & 10 & 03 & & \\
\hline Total & 20 & 32 & & \\
\hline \multicolumn{5}{|l|}{ Proteinuria } \\
\hline No & 14 & 23 & 0.021 & 0.885 \\
\hline Yes & 06 & 19 & & \\
\hline Total & 20 & 32 & & \\
\hline \multicolumn{5}{|l|}{ Pyuria } \\
\hline No & 12 & 27 & 3.900 & 0.048 \\
\hline Yes & 08 & 05 & & \\
\hline Total & 20 & 32 & & \\
\hline \multicolumn{5}{|l|}{ Nitrite } \\
\hline No & 12 & 28 & 3.809 & $0.051^{*}$ \\
\hline Yes & 08 & 04 & & \\
\hline Total & 20 & 32 & & \\
\hline \multicolumn{5}{|c|}{ Microscopic Pyuria } \\
\hline No & 11 & 29 & 6.907 & $0.009^{*}$ \\
\hline Yes & 09 & 03 & & \\
\hline Total & 20 & 32 & & \\
\hline
\end{tabular}

*Yate's correction was done. smearing by their faeces may increased the risk of UTI. Also, because of poor mobility, UTI may develop easily following urinary retention resulting from the difficulty in getting to the toilets to micturate in a few that may be urinary continent. Furthermore, the propensity to developing constipation in poorly mobile CP children may also have contributed to the higher risk of UTI in this group of children.

In the present study, we did not find any association between intellectual disability and UTI. We propose that cognitive ability to communicate the need to void as well as its effect on urinary continence attainment may not be as important as improving mobility among our CP children in order to reduce the prevalence of UTI.

In addition, we found that all the CP subjects with UTI are over-five children. These findings may probably result from recruitment bias as more $\mathrm{CP}$ patients that are over-fives $(75 \%)$ were recruited in our study.

Furthermore, UTI presents more symptomatically $-18 / 20,90 \%$ - in our CP patients, and therefore all efforts should be put in place to review symptoms of UTI among the CP patients when they come for follow-up in our clinics in order to confirm and treat a UTI and thus prevent its potential complications.

Escherichia coli have been shown to account for up to $75 \%$ of UTIs in all paediatric age groups followed by Klebsiella spp., Proteus spp. and Pseudomonas spp. [23]. As may be expected, Escherichia coli were also the commonest isolate $(9 / 20,45 \%)$ among our subjects with $\mathrm{CP}$ and the controls without CP $(2 / 2,100 \%)$ in the present study.

Previous studies [15-18,21] and the present one had shown that Escherichia coli is becoming highly resistant to the first line empirical antimicrobials for UTI, including cotrimoxazole, amoxicillin, nitrofuratoin and nalidixic acid. Its preserved sensitivity to the quinolones and ceftriazone and gentamycin may be explained by the fact that the quinolones are rarely prescribed for children and the parenteral routes of ceftriazone and gentamycin reduce the abuse of these two antibiotics. Although in vitro resistance may not necessarily means in vivo resistance, Chukwu et al. [15] had earlier summarized some of the common reasons for the emergence of resistance to the first line antimicrobials. These include a mix of drug resistance developed by the pathogens, low patient compliance, self-medication and potentially sub-therapeutic prescription by health workers [15]. The menace of substandard antibiotics which is common in developing countries cannot also be overemphasized.

We were able to detect VUR in one subject with CP. The causal relationship between this VUR and the possible neuropathic bladder of CP could not be ascertained because Urodynamic studies cannot be done in our centre. 
Table 6. Predictors of UTI among the children with cerebral palsy.

\begin{tabular}{|c|c|c|c|c|c|}
\hline \multirow{2}{*}{ Variable } & \multicolumn{2}{|c|}{ UTI } & \multicolumn{3}{|c|}{ Univariate } \\
\hline & Positive n (\%) & Negative n (\%) & OR & p-value & $95 \%$ CI \\
\hline \multicolumn{6}{|l|}{ Age in years } \\
\hline$\leq 5$ years & $0(0.0)$ & $13(100.0)$ & \multirow{2}{*}{ NA } & & \\
\hline$>5$ years & $20(51.3)$ & $19(48.7)$ & & & \\
\hline \multicolumn{6}{|l|}{ GMD type } \\
\hline Mild & $2(6.7)$ & $28(93.3)$ & & & \\
\hline Moderate to severe & $18(81.8)$ & $4(18.2)$ & 54.81 & 0.014 & $2.27-1324.00$ \\
\hline \multicolumn{6}{|l|}{ Haematuria } \\
\hline NO & $10(25.6)$ & $29(74.4)$ & & & \multirow{2}{*}{$0.14-19600.00$} \\
\hline YES & $10(76.9)$ & $3(23.1)$ & 53.18 & 0.188 & \\
\hline \multicolumn{6}{|l|}{ Pyuria } \\
\hline NO & $12(30.8)$ & $27(69.2)$ & & & \\
\hline YES & $8(61.5)$ & $5(38.5)$ & 2.39 & 0.714 & $0.02-250.23$ \\
\hline \multicolumn{6}{|l|}{ Microscopic pyuria } \\
\hline NO & $11(27.5)$ & $29(72.5)$ & & & \\
\hline YES & $9(75.0)$ & $3(25.0)$ & 2.00 & 0.803 & $0.01-441.62$ \\
\hline \multicolumn{6}{|l|}{ Flank pain } \\
\hline $\mathrm{NO}$ & $10(28.6)$ & $25(71.4)$ & & & \\
\hline YES & $10(58.8)$ & $7(41.2)$ & 3.01 & 0.562 & $0.07-125.01$ \\
\hline \multicolumn{6}{|l|}{ Dysuria } \\
\hline NO & $12(27.3)$ & $32(72.7)$ & \multirow{2}{*}{ NA } & & \\
\hline YES & $8(100.0)$ & $0(0.0)$ & & & \\
\hline \multicolumn{6}{|l|}{ Constipation } \\
\hline NO & $7(22.6)$ & $24(77.4)$ & & & \\
\hline YES & $13(61.9)$ & $8(38.1)$ & 0.44 & 0.764 & $0.002-99.488$ \\
\hline \multicolumn{6}{|l|}{ Nitrite } \\
\hline NO & $12(30.0)$ & $28(70.0)$ & & & \\
\hline YES & $8(66.7)$ & $4(33.3)$ & 0.05 & 0.237 & $0.00-7.37$ \\
\hline
\end{tabular}

$\mathrm{NA}=$ Not available.

\section{Limitation of the Study}

A larger population of children with $\mathrm{CP}$ could have made the prevalence of UTI as found in the present study more representatives in this group of children.

Urodynamic study was not performed on the subjects studied and so the exact judgment about predisposing lesions could not be ascertained.

Intelligence Quotients was also only tested among $\mathrm{CP}$ children between the ages of $6-11$ years because other evaluation methods are yet to be validated and standardized for use in Nigerian children.

\section{CONCLUSION}

The present study would sum up to indicate that there is a high prevalence of UTI among our children with CP, especially among those with severe immobility. Therefore, concerted efforts should therefore be put in place for effective physiotherapy aimed at attaining the great- est possible mobility and independence among our children with $\mathrm{CP}$.

\section{REFERENCES}

[1] Taft, L.T. (1995) Cerebral palsy. Pediatrics in Review, 16, 411-418.

[2] Reid, C.J. and Borzyskowski, M. (1993) lower urinary tract dysfunction in cerebral palsy. Archives of Disease in Childhood, 68, 739-742. http://dx.doi.org/10.1136/adc.68.6.739

[3] Drigo, P., Seren, F., Artibani, W., Laverda, A.M., Battistella, P.A. and Zacchello, G. (1988) Neurogenic vesicoureteral dysfunction in children with cerebral palsy. The Italian Journal of Neurological Sciences, 9, 151-154. http://dx.doi.org/10.1007/BF02337462

[4] Mayo, M.E. (1992) Lower urinary tract dysfunction in cerebral palsy. Journal of Urology, 142, 419-420.

[5] Bross, S., Pomer, S., Döderlein, L., Knoll, T., Michel, M.S., 
Staehler, G., Gerner, H.J. and Alken, P. (2004) Urodynamic findings in patients with infantile cerebral palsy. Aktuelle Urologie, 35, 54-57. http://dx.doi.org/10.1055/s-2003-812521

[6] Fahimzad, A., Babaied, D., Ghoroubi, J., Zahed, G.H. and Rafiei, T. (2013) Common infections among disabled children admitted to hospital. Archives of Pediatric Infectious Diseases, 1, 71-74. http://dx.doi.org/10.5812/pedinfect.9075

[7] Hellquist, J.M., McKinney Jr, R.E. and Worley, G. (1985) Urinary tract infections in cerebral patients. Pediatric Research, 5, 295. http://dx.doi.org/10.1203/00006450-198504000-01140

[8] Ozturk, M., Oktem, F., Kisioglu, N., Demirci, M., Altuntas, I., Kutluhan, S. and Dogan, M. (2006) Bladder and bowel control in children with cerebral palsy: Case-control study. Croatian Medical Journal, 47, 264-270.

[9] Palisano, R., Rosenbaum, P., Walter, S., Russell, D., Wood, E. and Galuppi, B. (1997) Development and reliability of a system to classify gross motor function in children with cerebral palsy. Developmental Medicine and Child Neurology, 39, 214-223. http://dx.doi.org/10.1111/j.1469-8749.1997.tb07414.x

[10] Njokanma, O.F. and Nkanginieme, K.E.O. (2007) Growth and development. In: Azubuike, J.C. and Nkanginieme, K.E.O., Eds., Paediatrics and Child Health in a Tropical Region, African Educational Services, Owerri, 56-69.

[11] Benninga, M., Candy, D.C., Catto-Smith, A.G., Clauden, G., Loening-Baucke, V., DiLorenzo, C., Nurko, S. and Staiano, A. (2005) The Paris Consensus on Childhood Constipation Terminology (PACCT) Group. Journal of Pediatric Gastroenterology and Nutrition, 40, 273-275. http://dx.doi.org/10.1097/01.MPG.0000158071.24327.88

[12] American Psychiatric Association (1994) Diagnostic and statistical manual of mental disorders. A.P.A., Washington DC, 1.

[13] Cheesebrough, M. (2002) Examination of urine. District laboratory practice in tropical countries. Cambridge University Press, Cambridge.

[14] Ajasin, M.A. and Adegbola, R.A. (1998) Asymptomatic bacteriuria in children with sickle cell anaemia. Nigerian Journal of Paediatrics, 15, 19-25.
[15] Chukwu, B.F., Okafor, H.U. and Ikefuna, A.N. (2009) Asymptomatic bacteriuria in children with sickle cell anemia at The University of Nigeria teaching hospital, Enugu, South East, Nigeria. Italian Journal of Pediatrics, 9, 45.

[16] Asinobi, A.O., Fatunde, O.J., Brown, B.J., Osinusi, K. and Fasina, N.A. (2003) Urinary tract infection in febrile children with sickle cell anaemia in Ibadan, Nigeria. $\mathrm{An}$ nals of Tropical Paediatrics, 23, 129-134. http://dx.doi.org/10.1179/027249303235002198

[17] Okunola, P.O., Ibadin, M.O., Ofovwe, G.E. and Ukoh, G. (2012) Co-existence of urinary tract infection and malaria among under five years old: A report from Benin city, Nigeria. Saudi Journal of Kidney Disease and Transplantation, 23, 629-634.

[18] Musa-Aisien, A.S., Ibadin, M.O., Ukoh, G. and Akpede, G.O. (2003) Prevalence and antimicrobial sensitivity pattern in urinary tract infection in febrile under-5s at a children's emergency unit in Nigeria. Annals of Tropical Paediatrics, 23, 39-45. http://dx.doi.org/10.1179/000349803125002850

[19] Iduoriyekemwen, N.J., Sadoh, W.E. and Sadoh, A.E. (2012) Asymptomatic bacteriuria in HIV positive Nigerian children. Journal of Medicine and Biomedical Research, 11, 88-94.

[20] Oyedeji, G.A. (1989) The pattern of infections in children with severe protein energy malnutrition. Nigerian Journal of Paediatrics, 16, 55-61.

[21] Rabasa, A. and Shattima, D. (2002) Urinary tract infection in severely malnourished children at the University of Maiduguri Teaching Hospital. Journal of Tropical Pediatrics, 48, 359-361. http://dx.doi.org/10.1093/tropej/48.6.359

[22] Foxman, B. (2002) Epidemiology of urinary tract infections: Incidence, morbidity, and economic costs. American Journal of Medicine, 113, 5S-13S. http://dx.doi.org/10.1016/S0002-9343(02)01054-9

[23] Elder, J.S. (2004) Urinary tract infections. In: Behrman, R.E., Vaughan, V.C. and Jensen, H.B., Eds., Nelson Textbook of Paediatrics, W.B., Saunders, Philadelphia, 17851790 